\title{
Potential drug-drug interactions among elderly in-patients with cardiac illness at a tertiary care centre
}

\author{
Akanksha Mathur ${ }^{1 *}$, Nidhi Jain ${ }^{2}$, Achal Sharma ${ }^{3}$, Prashant C. Shah ${ }^{4}$
}

\begin{abstract}
${ }^{1}$ Department of Pharmacology, AIIMS, Bhopal, Madhya Pradesh, India
${ }^{2}$ Department of Pharmacology, Gandhi Medical College, Bhopal, Madhya Pradesh, India

${ }^{3}$ Department of Cardiology, GSMC and KEM Hospital, Mumbai, Maharashtra, India

${ }^{4}$ Department of Pharmacology, Baroda Medical College, Vadodara, Gujarat, India
\end{abstract}

Received: 26 December 2019

Revised: 11 February 2020

Accepted: 12 February 2020

*Correspondence:

Dr. Akanksha Mathur,

Email: akanksha.mathur1@gmail.com

Copyright: (c) the author(s), publisher and licensee Medip Academy. This is an open-access article distributed under the terms of the Creative Commons Attribution Non-Commercial License, which permits unrestricted non-commercial use, distribution, and reproduction in any medium, provided the original work is properly cited.

\begin{abstract}
Background: Drug interactions are major cause of concern in hospitalized patients with cardiac illness especially in elderly population. Therefore, the study was conducted to determine the prevalence and pattern of potential drug-drug interactions (pDDI) and risk factors, if any.

Methods: It was a prospective observational study involving 75 elderly in-patients with cardiac diseases. IHEC approval was taken before commencement of study and written informed consent was taken from all the study participants. Data was collected using structured data collection tool. pDDI were analyzed using MEDSCAPE databse. Data was analyzed using SPSS 20.0 in terms of descriptive statistics. Pearson correlation coefficient was used to find the association between the risk factors and potential DDIs. P value of $\leq 0.05$ was considered statistically significant.

Results: The prevalence of pDDI was found to be 100\%. Total 593 pDDI and 33 interacting drug pairs were observed in the study. The common drug interacting pairs were aspirin and furosemide $140(23.61 \%)$, followed by aspirin+ enalapril 98 (16.53\%) and heparin and clopidogrel $56(9.44 \%)$. Majority of pDDI $480(81 \%)$ were found to be of moderate severity. A significant association was documented between length of hospital stay $(\mathrm{p}=0.041)$ and occurrence of pDDI. A statistically significant correlation $(r=0.621 ; p<0.01)$ was noted between number of drugs prescribed and total number of pDDIs.

Conclusions: A high prevalence of pDDI was observed. The prevalence rate is directly related to number of drugs prescribed and length of hospital stay. Therefore, close monitoring of hospitalized patients is recommended.
\end{abstract}

Keywords: Cardiac, Drug interactions, Elderly, Polypharmacy

\section{INTRODUCTION}

Drug interactions remains as one of the key issue to be addressed among patients with multiple drug therapy. When two or more drugs interact with each other, it may either alter the effectiveness or the toxicity profile of the concomitantly administered drug. This may sometimes prove as beneficial effect or may cause negative consequences. It has been documented that drug interactions are responsible for adverse drug reactions, hospitalization or increased duration of hospitalization, drug toxicity or reduced/abolished drug response. The severity of drug interactions may vary from mild to serious life threatening conditions.

The drugs may interact with pharmacokinetic parameters of other drugs or alter the pharmacodynamics. In some cases, both the kinetics and dynamics are altered. 
Cardiac diseases encompass a wide spectrum of illnesses ranging from hypertension to acute coronary syndrome or arrhythmias. With the sedentary lifestyle and poor dietary habits, cardiac diseases are gaining attention across the globe. The prevalence of heart diseases in India has increased by more than $50 \%$ from 1990 till date. ${ }^{1}$ It has become as the topmost cause of deaths in Indian population. ${ }^{2}$ Cardiac diseases are usually associated with multiple risk factors. And therefore, it becomes prudent to treat not just the disease but associated risk factors as well. This leads to increase in the number of medicines prescribed, especially in hospitalized patients, thus accounting for drug interactions. Elderly are even more prone to develop negative effects of drug drug interactions. $^{3}$ The risk-benefit ratio therefore becomes necessary to implement whenever multiple drugs are administered together.

Various studies have reported the prevalence of potential drug-drug interactions in patients with cardiac illness ranging from $65 \%$ to $99 \%$ across the globe. ${ }^{4}$ However, very few studies have been conducted on Indian population. Therefore, the present study has been designed to determine the prevalence and pattern of potential drug-drug interactions (pDDI) and to assess predisposing factors, if any.

\section{METHODS}

It was a prospective observational study conducted at SSG Hospital, Baroda, a tertiary care teaching hospital for six months. Approval from institutional ethics committee was taken before the commencement of study. Written informed consent was taken from every patient who participated in the study.

\section{Inclusion and exclusion criteria}

The study included all the elderly in-patients of either gender and age admitted in medicine wards, cardiac care unit and intensive care unit diagnosed with any cardiac illness during the study period. The patients admitted for observation purpose were excluded from the study. Sample size was calculated based on convenient sampling technique.

The relevant data collected from case sheets was properly documented in a separate data collection form. The obtained data was then analyzed for identification of potential drug-drug interactions (pDDI) and its pattern using MEDSCAPE database, a computerized DDI database system. The database has inbuilt software that detects and categorize DDI based on severity. A major interaction focuses on the need of using an alternative drug, moderate interaction emphasizes the need to monitor the patient closely and minor interactions do not warrant any change in the treatment. Additionally, the risk factors predisposing to DDI are studied separately.

\section{Statistical analysis}

Data was analysed in terms of descriptive statistics using mean $\pm S D$, frequency and percentage. Pearson correlation coefficient was used to find the association between the risk factors and potential DDIs, $\mathrm{p}$ value of $\leq 0.05$ was considered statistically significant and $\leq 0.01$ as highly statistically significant. The statistical analysis was done using SPSS software, version 20.0.

\section{RESULTS}

\section{Patients' general characteristics}

Total 75 patients were enrolled in the study. Out of 75 patients, $50(67 \%)$ were women and $25(33 \%)$ were men. Majority of patients $38(51 \%)$ were from the age group 60-69 years. The most common diagnosis was ischemic heart disease $38(51 \%)$ followed by corpulmonale 11 $(15 \%)$, congestive heart failure $9(12 \%)$ and atrial fibrillation 9 (12\%) (Figure 1). Patients' average duration of stay in the hospital was $5.18 \pm 0.70$. Dyslipidemia 50 $(67 \%)$ was found to be the most common co-morbidity associated followed by diabetes mellitus 24 (32\%). Total 905 drugs were prescribed in 75 patients. Average number of drugs per prescription was $12.04 \pm 1.41$.

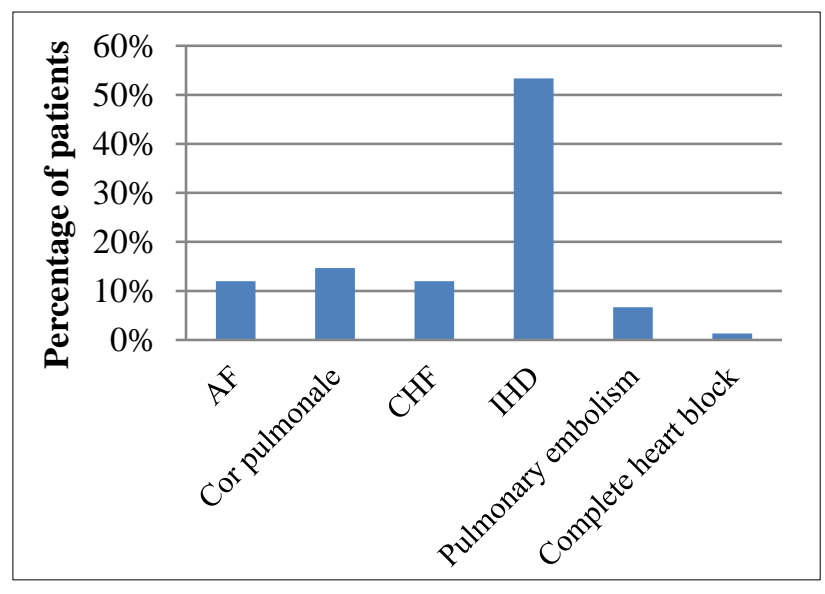

Figure 1: Diagnosis of patients.

\section{Prevalence of pDDI}

Out of total 75 patients enrolled in the study, all the patients were found to have at least one pDDI. The prevalence of pDDI was $100 \%$ in our study. Total 593 pDDI were identified in 75 patients. Majority of them were found to be of moderate severity (Figure 2). $\leq 5$ pDDI was found in $32(43 \%)$ patients, 6-10 pDDI in $25(33 \%)$ patients and $\geq 10$ pDDI in $18(24 \%)$ of patients. Average number of pDDI per patient was 7.9 \pm 2.12 .

\section{Interacting drug pairs}

Total 33 drug interacting pairs were observed in the study. The common drug interacting pairs were aspirin + 
furosemide 140 (23.61\%), followed by aspirin and enalapril $98(16.53 \%)$ and heparin and clopidogrel 56 $(9.44 \%)$. Majority of pDDI identified were due to pharmacodynamic mechanisms 383 (64.59\%). 87 $(14.67 \%)$ pDDI were caused due to pharmacokinetic interaction between drugs and rest were because of both the kinetic as well as dynamic interactions.

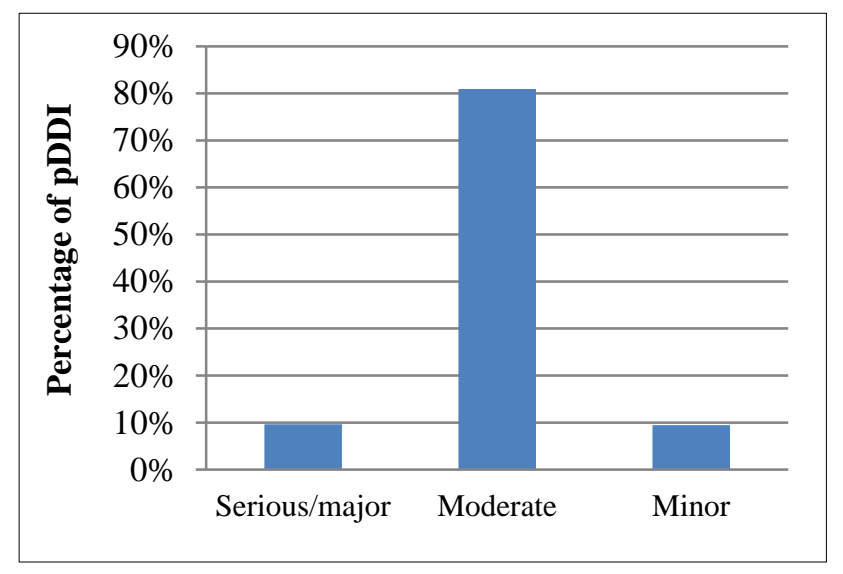

Figure 2: Severity of pDDI.

\section{Risk factors predisposing $\mathrm{pDDI}$}

pDDI were found to be more commonly present in women. Moreover, the patients prescribed $\geq 8$ medicines had more number of pDDI. The patients having $\geq 4$ days of hospital stay were found to have more number of pDDI.

A significant $(\mathrm{p}<0.05)$ association was documented between length of hospital stay and occurrence of pDDI. However, it was found that the patients taking eight or more drugs were highly significantly associated with occurrence of pDDI. A positive linear correlation with statistically highly significant value was noted between number of drugs prescribed and total number of pDDIs (Table 1).

Table 1: Predisposing risk factors for pDDI.

\begin{tabular}{|llll|}
\hline Risk factor & $\begin{array}{l}\chi^{2} \\
\text { value }\end{array}$ & $\begin{array}{l}\mathbf{P} \\
\text { value }\end{array}$ & $\begin{array}{l}\text { r value (Pearson } \\
\text { correlation) }\end{array}$ \\
\hline $\begin{array}{l}\text { Length of } \\
\text { hospital stay }\end{array}$ & 5.025 & 0.041 & - \\
\hline $\begin{array}{l}\text { Patients on } \\
\mathbf{8} \text { medicines }\end{array}$ & 23.04 & $<0.01$ & 0.621 \\
\hline
\end{tabular}

\section{DISCUSSION}

Study revealed very high prevalence of drug-drug interactions in the cardiac in-patients as supported by other studies. ${ }^{4-7}$ The high prevalence may be due to presence of various risk factors in hospitalized patients. Elderly age group, cardiac illness and associated multiple co-morbidities which in turn lead to polypharmacy, may result into development of drug-drug interactions. As evident from the study, average number of medicines prescribed per patient was quite high (12.04 \pm 1.41$)$. Moreover, in this study all the severity grades of pDDI were considered while many studies have listed only the significant ones or clinically relevant ones. The study reported high prevalence of pDDI in women than men. According to a latest study woman are more prone to develop drug-drug interactions. ${ }^{8}$

Majority of drug interactions reported in the study were of moderate to major severity as also seen in various other studies. ${ }^{6,7}$ (Table 2). Also, the documentation status varied from fair to good evidence. Similar findings were noted in other studies as well. ${ }^{6,9,10}$

Table 2: Majorly serious drug interacting pairs.

\begin{tabular}{|ll|}
\hline Drug pairs & Risk \\
\hline $\begin{array}{l}\text { Aspirin and } \\
\text { enalapril }\end{array}$ & $\begin{array}{l}\text { Pharmacodynamic } \\
\text { antagonism. Decrease in renal } \\
\text { function. Diminish the } \\
\text { antihypertensive effect of } \\
\text { ACE inhibitors. }\end{array}$ \\
\hline $\begin{array}{l}\text { Azithromycin and } \\
\text { digoxin }\end{array}$ & $\begin{array}{l}\text { Increase in the level or effect } \\
\text { of digoxin }\end{array}$ \\
\hline $\begin{array}{l}\text { Digoxin and } \\
\text { metoprolol }\end{array}$ & $\begin{array}{l}\text { Digoxin increases toxicity of } \\
\text { metoprolol by unspecified } \\
\text { interaction } \\
\text { mechanism. Increase risk of } \\
\text { bradycardia. }\end{array}$ \\
\hline $\begin{array}{l}\text { Warfarin and } \\
\text { enoxaparin }\end{array}$ & Bleeding \\
\hline $\begin{array}{l}\text { Azithromycin and } \\
\text { enoxaparin }\end{array}$ & Increased effect of enoxaparin \\
\hline $\begin{array}{l}\text { Azithromycin and } \\
\text { warfarin }\end{array}$ & Increased effect of warfarin \\
\hline $\begin{array}{l}\text { Atenolol and } \\
\text { metoprolol }\end{array}$ & $\begin{array}{l}\text { Increase in anti-hypertensive } \\
\text { effect }\end{array}$ \\
\hline
\end{tabular}

Most commonly observed mechanism of drug-drug interactions in this study was pharmacodynamic as also supported by other studies. ${ }^{4,5}$ This is in contrast to the finding reported in a few studies. ${ }^{11-13}$

Polypharmacy is widely prevalent in hospitalized patients and although it poses threat to patients' overall recovery, it sometimes becomes unavoidable. Study showed the concomitant use of multiple medicines as high as 12 . Moreover, a positive association has been observed in the study between the number of medicines prescribed and development of drug-drug interactions. These findings are consistent with previously conducted studies. ${ }^{6,14,15}$

Also, it has been evident from the study, the longer the duration of stay of patient in the hospital the more the risk of developing pDDI. This indirectly correlates to the number of medicines prescribed. This finding may suggest more vigilant attitude of healthcare givers towards prescribing medicines especially in elderly patients. Not 
only the prescribing of medicines be more carefully chosen but also the therapy be monitored more closely for any drug interaction.

The most common drug interaction found in our study was aspirin and furosemide which results in attenuation of the diuretic and venodilatory effect of furosemide and may cause acute renal failure, is established (Table 3). However, the clinical relevance of this interaction has not been much studied. Another, important interaction noted was aspirin and enalapril which is of major severity. Theoretically it has been postulated that aspirin may reduce the beneficial effects of ACE inhibitors in patients with heart failure. But the information is limited by the retrospective nature of the analyses and does not accurately establish the association. Interaction between anti platelet and anticoagulant is well known and may predispose to bleeding. Presence of an enzyme inducer or inhibitor in the treatment regimen may increase the chances of drug toxicity or reduced effect.

Table 3: Drug-drug interaction pairs.

\begin{tabular}{|lllll|}
\hline Drug pairs & Severity & Frequency (n) & Risk & Documentation \\
\hline Aspirin and furosemide & Moderate & 140 & Fluid retention & Good \\
\hline Aspirin and enalapril & Major & 98 & Renal dysfunction & Fair \\
\hline Heparin and clopidogrel & Moderate & 56 & Bleeding & Good \\
\hline Aspirin and clopidogrel & Moderate & 47 & Bleeding & Fair \\
\hline Aspirin and heparin & Moderate & 42 & Bleeding & Good \\
\hline Heparin and enalapril & Moderate & 32 & Hyperkalemia & Fair \\
\hline Spironolactone and enalapril & Moderate & 23 & Hyperkalemia & Good \\
\hline Aspirin and metoprolol & Moderate & 12 & $\begin{array}{l}\text { Decreased metoprolol effect, } \\
\text { hyperkalemia }\end{array}$ & Fair \\
\hline $\begin{array}{l}\text { Azithromycin and } \\
\text { atorvastatin }\end{array}$ & Moderate & 4 & $\begin{array}{l}\text { Increase in the level or effect } \\
\text { of atorvastatin }\end{array}$ & Good \\
\hline Digoxin and metoprolol & Major & 3 & Bradycardia, hyperkalemia & Good \\
\hline
\end{tabular}

Therefore, to deal with the issue of drug-drug interactions, a more vigilant and careful approach should be incorporated while prescribing medicines in elderly. Use of software for easy detection of drug-drug interactions may be incorporated as screening procedure. Alternatively, clinical pharmacist may be involved for assessment of pDDI. Frequent evaluation of prescriptions in structural manner to evaluate pDDI and lab investigations for detecting drug interactions can be utilized.

However, the study has certain limitations. The findings of the study may not be generalized as it was a single centre study involving a small sample size. However, the study was prospectively conducted so credibility of database can be ensured. Secondly, the study reports only potential drug-drug interactions that may not be clinically relevant. However, it does provide important findings of drug interactions that may be prevented, minimized or managed if the healthcare givers have the knowledge of such interactions

\section{CONCLUSION}

High prevalence of pDDI in cardiac inpatients necessitates the importance of appropriate preventive strategies. Online databases can be one of the quickest and easiest ways to assess by clinicians. However, it cannot replace appropriate therapeutic decision making particularly when the patient is suffering from multiple co morbidities. Close monitoring for adverse effects should be done in all the patients.
Funding: No funding sources

Conflict of interest: None declared

Ethical approval: The study was approved by the Institutional Ethics Committee

\section{REFERENCES}

1. Sharma DC. Heart disease, stroke top killers in India. Available at: https://www.thehindubusinessline.com/ news/science/heart-disease-stroke-among-top-killersin-india/article24935985.ece Accessed 24 December 2019.

2. Chauhan S, Aeri BT. The rising incidence of cardiovascular diseases in India: assessing its economic impact. J Preventive Cardiol. 2015;4:73540.

3. Cascorbi I. Drug interactions--principles, examples and clinical consequences. Dtsch Arztebl Int. 2012;109:546-56.

4. Khan MZ, Sridhar SB, Gupta PK. Assessment of Potential Drug-Drug Interactions in Hospitalized Cardiac Patients of a Secondary Care Hospital in the United Arab Emirates. J Res Pharm Pract. 2019;8:204.

5. Shanbhag AD, Hema NG, Sadananda KS. Potential drug-drug interactions among hospitalized cardiac patients. Int J Basic Clin Pharmacol. 2016;5:2251-6.

6. Noor S, Ismail $\mathrm{M}$, Ali Z. Potential drug-drug interactions among pneumonia patients: do these matter in clinical perspectives? BMC Pharmacol Toxicol. 2019;20:45.

7. Shareef J, Menezes SL, Bhat T. A study on potential drug - drug interactions in medicine department of a 
multispeciality teaching hospital. J Drug Delivery Therapeut. 2017;7:81-7.

8. Correia RB, Kohler LPA, Mattos MM, Rocha LM. City-wide electronic health records reveal gender and age biases in administration of known drug-drug interactions. NPJ Digit Med. 2019;2:74.

9. Subramanian A, Adhimoolam M, Kannan S. Study of drug-drug interactions among the hypertensive patients in a tertiary care teaching hospital. Perspect Clin Res. 2018;9:9-14.

10. Murtaza G, Khan MY, Azhar S, Khan SA, Khan TM. Assessment of potential drug-drug interactions and its associated factors in the hospitalized cardiac patients. Saudi Pharm J. 2016;24:220-5.

11. Sharma S, Chhetri HP, Alam K. A study of potential drug-drug interactions among hospitalized cardiac patients in a teaching hospital in Western Nepal. Indian J Pharmacol. 2014;46:152-6.

12. Vonbach P, Dubied A, Krähenbühl S, Beer JH. Prevalence of drug drug interactions at hospital entry and during hospital stay of patients in internal medicine. Eur J Intern Med. 2008;19:413-20.

13. Aparasu R, Baer R, Aparasu A. Clinically important potential drug-drug interactions in outpatient settings. Res Social Adm Pharm. 2007;3:426-37.

14. Ismail M, Aziz S, Noor S, Haider I, Shams F, Haq I, et al. Potential drug-drug interactions in pediatric patients admitted to intensive care unit of Khyber teaching hospital, Peshawar, Pakistan: a crosssectional study. J Crit Care. 2017;40:243-50.

15. Stoll P, Kopittke L. Potential drug-drug interactions in hospitalized patients undergoing systemic chemotherapy: a prospective cohort study. Int J Clin Pharm. 2015;37:475-84

Cite this article as: Mathur A, Jain N, Sharma A, Shah PC. Potential drug-drug interactions among elderly in-patients with cardiac illness at a tertiary care centre. Int J Basic Clin Pharmacol 2020;9:470-4. 